\title{
Lead-Free Piezoelectric Diaphragm Biosensors Based on Micro-Machining Technology and Chemical Solution Deposition
}

\author{
Xiaomeng $\mathrm{Li}^{1}$, Xiaoqing $\mathrm{Wu}^{1, *}$, Peng Shi ${ }^{1}$ and Zuo-Guang Ye ${ }^{1,2}$ \\ Received: 22 November 2015; Accepted: 31 December 2015; Published: 12 January 2016 \\ Academic Editor: Alexander Star \\ 1 Electronic Materials Research Laboratory, Key Laboratory of the Ministry of \\ Education \& International Center for Dielectric Research, Xi'an Jiaotong University, Xi'an 710049, China; \\ leemoon56@stu.xjtu.edu.cn (X.L.); spxjy@mail.xjtu.edu.cn (P.S.); zye@sfu.ca (Z.-G.Y.) \\ 2 Department of Chemistry and 4D LABS, Simon Fraser University, Burnaby, BC V5A 1S6, Canada \\ * Correspondence: xqwu@mail.xjtu.edu.cn; Tel.: +86-29-82665670
}

\begin{abstract}
In this paper, we present a new approach to the fabrication of integrated silicon-based piezoelectric diaphragm-type biosensors by using sodium potassium niobate-silver niobate $(0.82 \mathrm{KNN}-0.18 \mathrm{AN})$ composite lead-free thin film as the piezoelectric layer. The piezoelectric diaphragms were designed and fabricated by micro-machining technology and chemical solution deposition. The fabricated device was very sensitive to the mass changes caused by various targets attached on the surface of diaphragm. The measured mass sensitivity value was about $931 \mathrm{~Hz} / \mu \mathrm{g}$. Its good performance shows that the piezoelectric diaphragm biosensor can be used as a cost-effective platform for nucleic acid testing.
\end{abstract}

Keywords: piezoelectric diaphragm biosensor; lead-free; chemical solution deposition

\section{Introduction}

Over the past few decades, researchers have focused on developing sensors with high sensitivity and low limits of detection. As a result, a wide range of biosensors with different operational modalities have been demonstrated. In particular, label-free biosensors are suitable for rapid and real-time sensing applications. Many types of label-free biosensors, such as nanogap and microneedle biosensors, have been widely studied [1-8].

In recent years, piezoelectric devices have been widely used as micro-pumps, actuators, transducers and biosensors [9-18]. The high sensitivity quartz crystal micro-balance (QCM) has been successfully used in biosensors for many years [19-21]. However, the conventional crystal or bulk ceramic technology is insufficient to meet the increasing requirements of miniaturization and integration. Recently, the development of micro-machined piezoelectric biosensors has become a focus of attention because of their merits such as compact size, high sensitivity, label-free operation, rapid response and compatibility with integrated circuit techniques [22-27]. Piezoelectric biosensors are mass-sensitive which is detected by measuring the shift of resonant frequency of the devices $[25,28]$. When the reaction between the recognition layer immobilized on the diaphragm and the captured target biological species happens, the total mass of the piezoelectric film area will change which results in a corresponding resonant frequency shift [29].

Nowadays, most piezoelectric devices use lead-based materials such as $\mathrm{Pb}(\mathrm{Zr}, \mathrm{Ti}) \mathrm{O}_{3}$ (PZT) and $\mathrm{Pb}\left(\mathrm{Mg}_{1 / 3} \mathrm{Nb}_{2 / 3}\right) \mathrm{O}_{3}-\mathrm{PbTiO}_{3}$ (PMN-PT) because of their excellent piezoelectric properties. However, the toxicity of lead has raised concerns and research on lead-free piezoelectric biosensors is in great demanded. The traditional lead-free piezoelectric materials, such as $(\mathrm{K}, \mathrm{Na}) \mathrm{NbO}_{3}(\mathrm{KNN})$ and 
$(\mathrm{Bi}, \mathrm{Na}) \mathrm{TiO}_{3}(\mathrm{BNT})$, are not widely applied because of their weak electrical properties. During this work, we have successfully prepared a new lead-free piezoelectric biosensor by using the lead-free film of $0.82 \mathrm{~K}_{0.5} \mathrm{Na}_{0.5} \mathrm{NbO}_{3}-0.18 \mathrm{AgNbO}_{3}(0.82 \mathrm{KNN}-0.18 \mathrm{AN})$, which exhibited much improved electrical properties compared to pure KNN film [30].

\section{Results and Discussion}

\subsection{Characterization of the $0.82 \mathrm{KNN}-0.18$ AN Piezoelectric Layer}

The crystallization and electrical properties of the $0.82 \mathrm{KNN}-0.18 \mathrm{AN}$ piezoelectric film were analysed. Figure 1 shows the XRD pattern of the $0.82 \mathrm{KNN}-0.18 \mathrm{AN}$ film, indicating that the film possessed a pure perovskite phase, and no obviously secondary phases were observed. It can be seen that the film exhibited (100) preferential orientation.

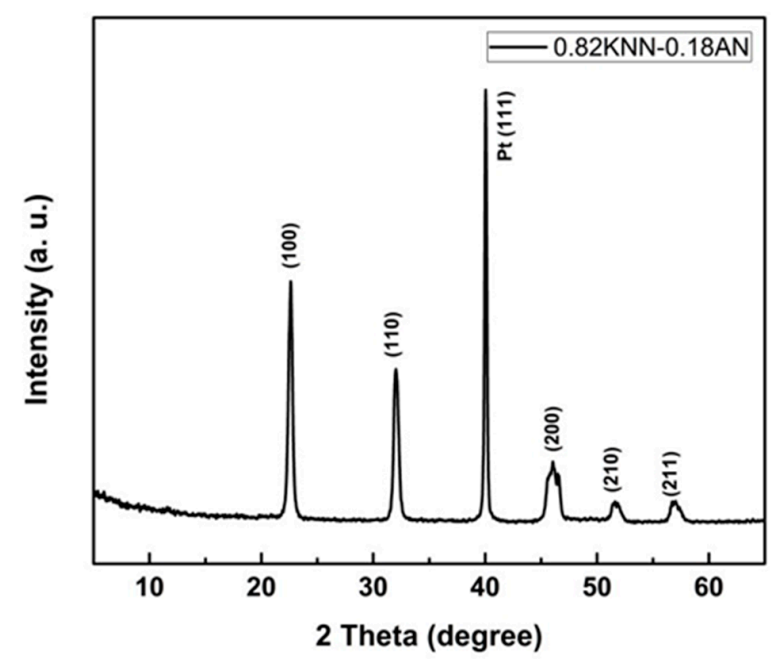

Figure 1. XRD pattern of the $0.82 \mathrm{KNN}-0.18 \mathrm{AN}$ film.

The surface and cross-sectional morphologies for the $0.82 \mathrm{KNN}-0.18 \mathrm{AN}$ film are shown in Figure 2. From the surface image, the average grain size of the $0.82 \mathrm{KNN}-0.18 \mathrm{AN}$ film was estimated to be about $200 \mathrm{~nm}$. From the cross-sectional image, the $0.82 \mathrm{KNN}-0.18 \mathrm{AN}$ film thickness was calculated to be about $2.16 \mu \mathrm{m}$. The crack-free film showed a good structure which ensured the good quality of the biosensor.

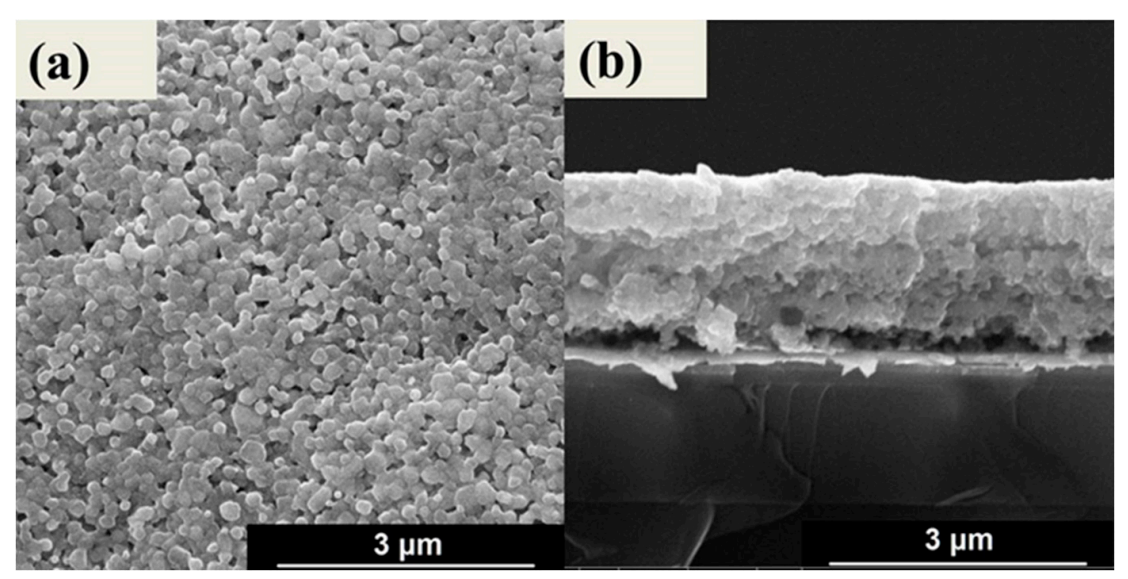

Figure 2. SEM images of the (a) surface; and (b) cross-sectional morphologies for the $0.82 \mathrm{KNN}-0.18 \mathrm{AN}$ film. 
The 0.82KNN-0.18AN film showed well defined P-E hysteresis loops while the pure KNN film deposited with the same method showed poorly shaped P-E hysteresis loops, as demonstrated in Figure 3. The remnant polarization (Pr) of the 0.82KNN-0.18AN film was calculated as $3.59 \mu \mathrm{C} / \mathrm{cm}^{2}$, at the applied electric field of $550 \mathrm{kV} / \mathrm{cm}$.

(a)

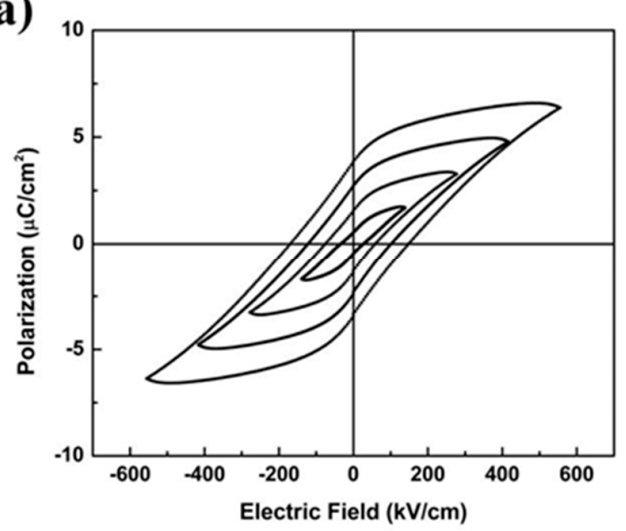

(b)

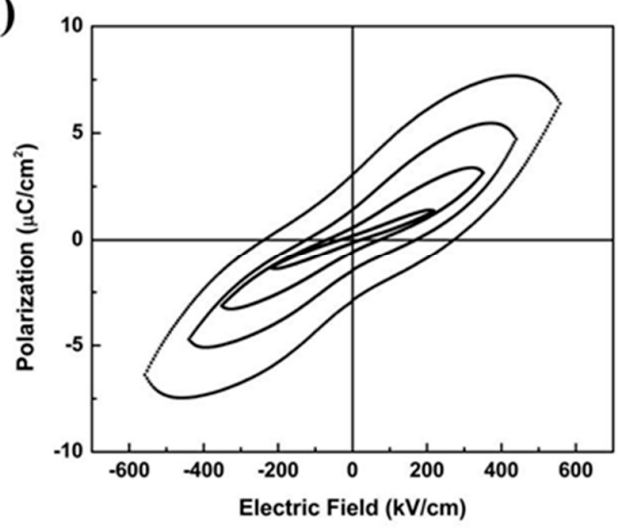

Figure 3. Hysteresis loops for the (a) 0.82KNN-0.18AN film; and (b) KNN film.

\subsection{Characterization of the Piezoelectric Diaphragm Biosensor}

Using the micro-machining process and deposition processing, piezoelectric diaphragm biosensors were successfully fabricated. As shown in Figure 4a, we can see that twenty individual biosensors were fabricated on a quarter of the 4 " wafer. The SEM top and bottom views of one individual biosensor were shown in Figure $4 b, c$.

(a)

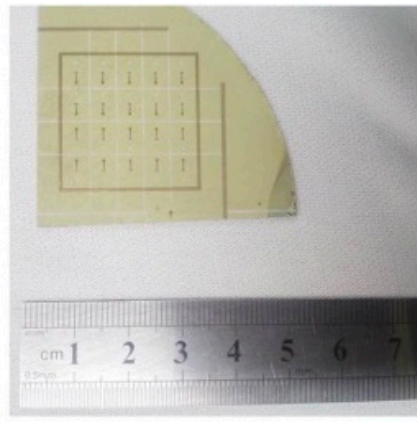

(c)

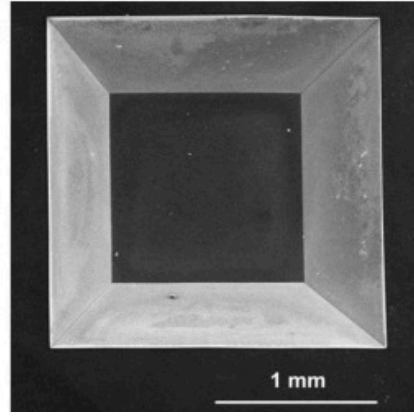

(b)

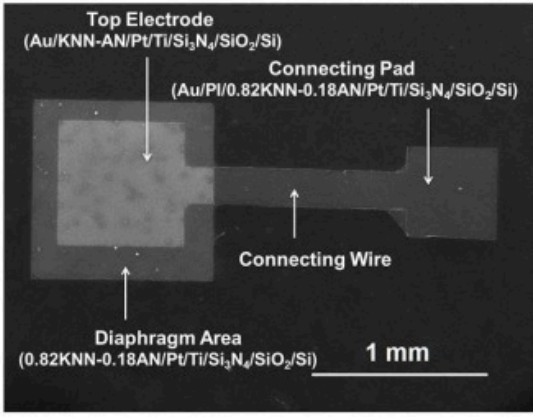

(d)

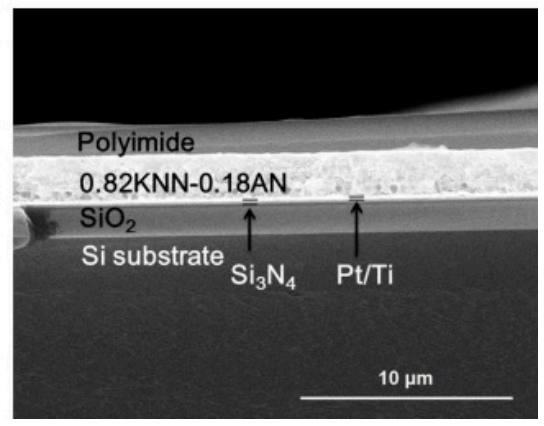

Figure 4. (a) Optical image; SEM images of the (b) front view; (c) back view; and (d) cross section of the fabricated biosensor.

The structures of the diaphragm area, top electrode, connecting wire and connecting pad are shown in detail. The length of the biosensor was $1 \mathrm{~mm}$ and the length of the top electrode was $0.7 \mathrm{~mm}$, which were the optimized parameters by the results of finite element simulation. The opening area of 
the chamber was much larger than that of the bottom diaphragm due to the anisotropic wet etching by $\mathrm{KOH}$. The dipping and washing in the immobilization process were much more convenient due to this enlarged opening chamber. The cross section of the biosensor was shown in Figure 4 d. Each layer of the multilayer structure was identified. The dense and crack-free $0.82 \mathrm{KNN}-0.18 \mathrm{AN}$ film ensured the high yield of the biosensor.

The test of mass sensitivity was carried out using a biosensor with a residual silicon thickness of about $25 \mu \mathrm{m}$. The detailed steps were as follows: firstly, we cleaned and modified the surface of a $\mathrm{Au}$ top electrode with piranha solution $\left(70 \% \mathrm{H}_{2} \mathrm{SO}_{4}: 30 \% \mathrm{H}_{2} \mathrm{O}_{2}\right)$. Secondly, we added $0.1 \mu \mathrm{L}$ of single-stranded DNA (ssDNA) (5'-6-FAM/CACAACAGACGGGCACACACTACT/C6-SH-3') solution with a concentration of $1 \mu \mathrm{g} / \mu \mathrm{L}$ on the surface of top electrode via Au-S reaction as mass load. Thirdly, we dried the device at $37^{\circ} \mathrm{C}$ for $30 \mathrm{~min}$ and hence $0.1 \mu \mathrm{g}$ mass was loaded. The above adding-drying steps were repeated three times until a total of $0.3 \mu \mathrm{L}$ of solution was added. The resonant frequencies were measured by an impedance analyzer (4294A, Agilent, Santa Clara, CA, USA) on the average resonant frequency values after three measurements. The relationship between resonant frequency and total mass load was thus obtained. The measured resonant frequencies were 79.965, 79.882, 79.803 and $79.681 \mathrm{kHz}$ for $0,0.1,0.2$, and $0.3 \mu \mathrm{g}$ total loaded mass, respectively, as shown in Figure 5 .

(a)

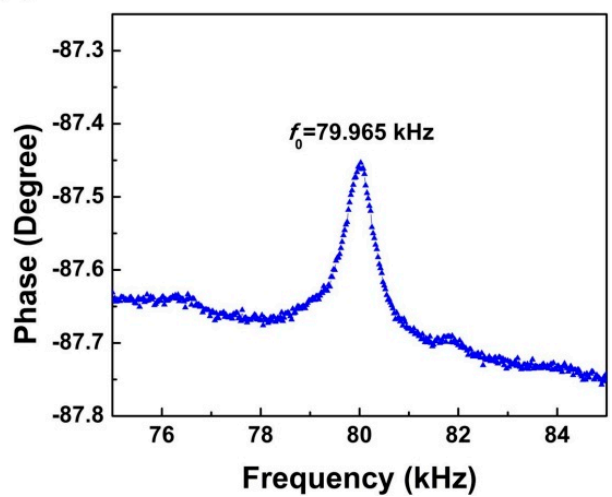

(c)

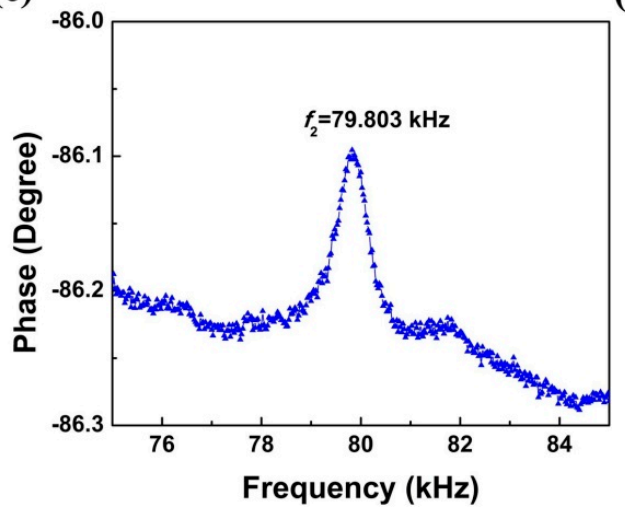

(b)

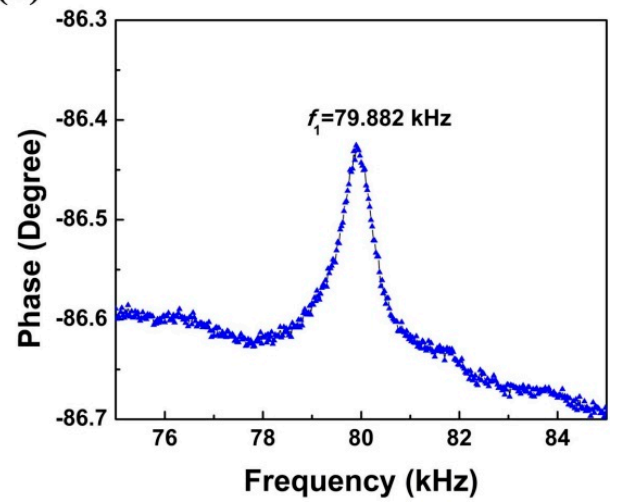

(d)

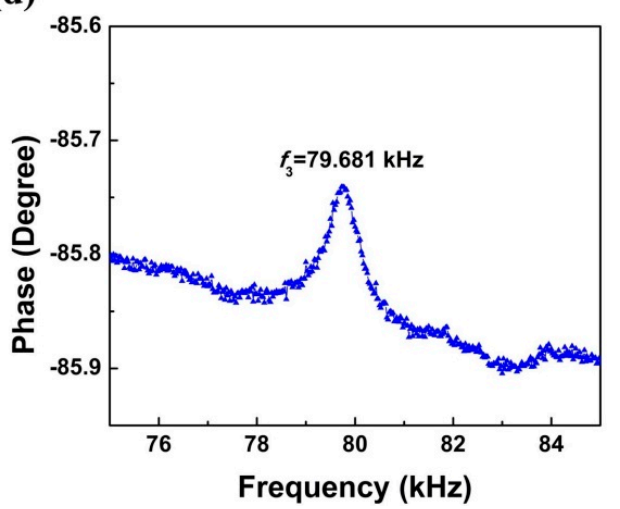

Figure 5. Resonant frequencies for different mass loaded: (a) no mass loaded; (b) $0.1 \mu \mathrm{g}$ total mass loaded; (c) $0.2 \mu \mathrm{g}$ total mass loaded and (d) $0.3 \mu \mathrm{g}$ total mass loaded.

A nearly linear relationship between the frequency shift and total mass load of the device was found, as shown in Figure 6. From the results, the mass sensitivity can be calculated as $S_{\mathrm{m}}=931 \mathrm{~Hz} / \mu \mathrm{g}$. $\mathrm{Xu}$ et al. [25] reported a biosensor array for immunoassay with a mass sensitivity of $6250 \mathrm{~Hz} / \mu \mathrm{g}$. Their piezoelectric diaphragm biosensors were based on PZT films and had smaller dimensions, which could increase the mass sensitivity. Zhao et al. [29] reported a lead-free piezoelectric biosensor based on polyvinylidene fluoride (PVDF) piezoelectric film with mass sensitivity of $185 \mathrm{~Hz} / \mu \mathrm{g}$, which was much smaller than our result. 


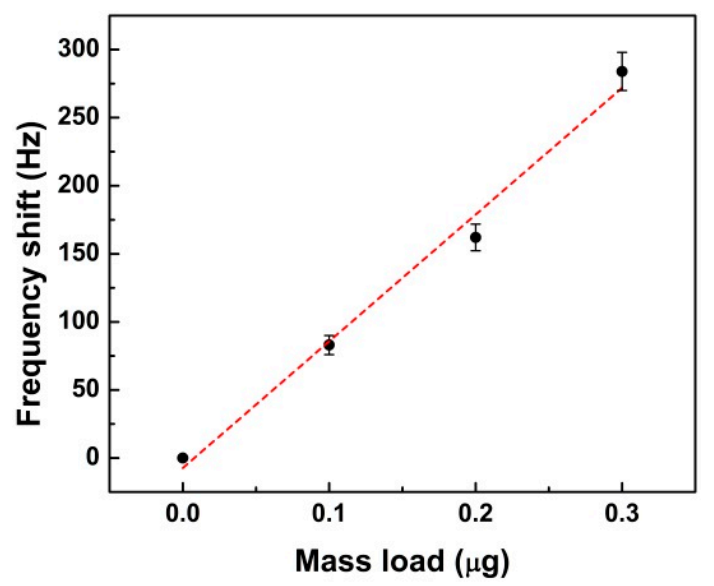

Figure 6. Relationship of the frequency shift and mass load.

The bio-sensing performance characteristics were also studied. In this test, the residual silicon thickness of the biosensor was about $20 \mu \mathrm{m}$. The detailed steps were as follows: (1) Thin gold film of $50 \mathrm{~nm}$-thick was deposited on the backside of the diaphragm to serve as the immobilization layer, which was then cleaned and modified by piranha solution treatment; (2) The capture DNA probe with the same concentration and sequence, which was used in the test of mass sensitivity, was immobilized on the gold surface. After $6 \mathrm{~h}$ of immobilization, the reaction surface was washed by DI water and dried under $\mathrm{N}_{2}$ flow; (3) 6-Mercapto-1-hexanol (MCH) blocking reagent was dropped for $2 \mathrm{~h}$ to improve the specificity. Then the reaction surface was washed by DI water and dried under $\mathrm{N}_{2}$ flow; (4) In the last step, target analytes which contain complementary DNA with the concentration of $1 \mu \mathrm{g} / \mu \mathrm{L}$ was added on the reaction surface for $0.5 \mathrm{~h}$ of nucleic acid hybridization. Then the excess analyte were washed away by DI water and the device was dried under $\mathrm{N}_{2}$ flow.

The resonant frequencies of the biosensor were measured immediately after each process, as shown in Figure 7. The original resonant frequency of the biosensor was noted as $f_{1}$, and the resonant frequencies after depositing gold film, adding probes, blockers and targets are $f_{2}, f_{3}, f_{4}$ and $f_{5}$, respectively. The resonant frequency for the plain, the deposition of gold, the immobilization of DNA probes, blockers and targets are 103.341, 102.635, 102.427, 102.176 and $101.988 \mathrm{kHz}$, respectively. The resonant frequency was continuously shifted to the lower domain, indicating an accumulated mass increasing during each process.

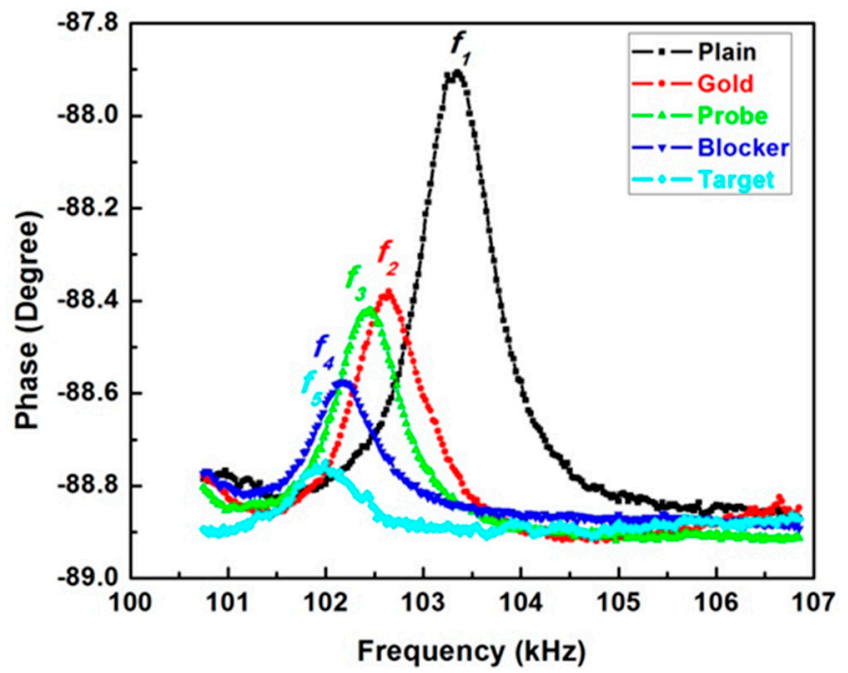

Figure 7. Frequency spectrum of the biosensor after different steps. 
Detailed frequency changes after each process for the biosensor were shown in Figure 8, of which the data points were calculated based on the average values after three measurements. Comparing the frequency decreased values for the biosensor, $\Delta f_{1}=f_{1}-f_{2}$ is the largest, which may be due to the high density of gold film. The resonant frequency shift values for the immobilization of probes, blockers and targets are $0.208,0.251$ and $0.188 \mathrm{kHz}$, respectively.

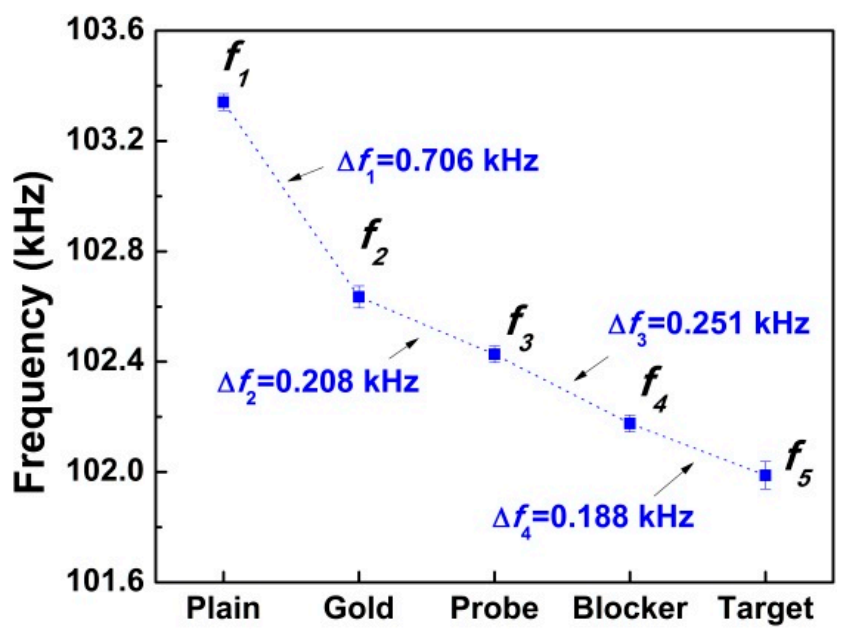

Figure 8. Frequency spectrum of the biosensor after different steps.

\section{Materials and Methods}

\subsection{Design of Device Structure and Sensing Principle}

The schematic structure and principle of the device are plotted in Figure 9. The piezoelectric biosensor was mainly composed of a supporting layer, piezoelectric layer, electrode layer and immobilization layer. For this piezoelectric diaphragm biosensor, the piezoelectric layer is driven by applying the voltage through the converse piezoelectric effect. The resonant frequency of biosensor after fabrication is $f_{0}$, owing to a mass change of the diaphragm, the resonant frequency will decrease to $f$. The resonant frequency shift $\left(f-f_{0}\right)$ could be calculated, and thus the corresponding mass could be determined.

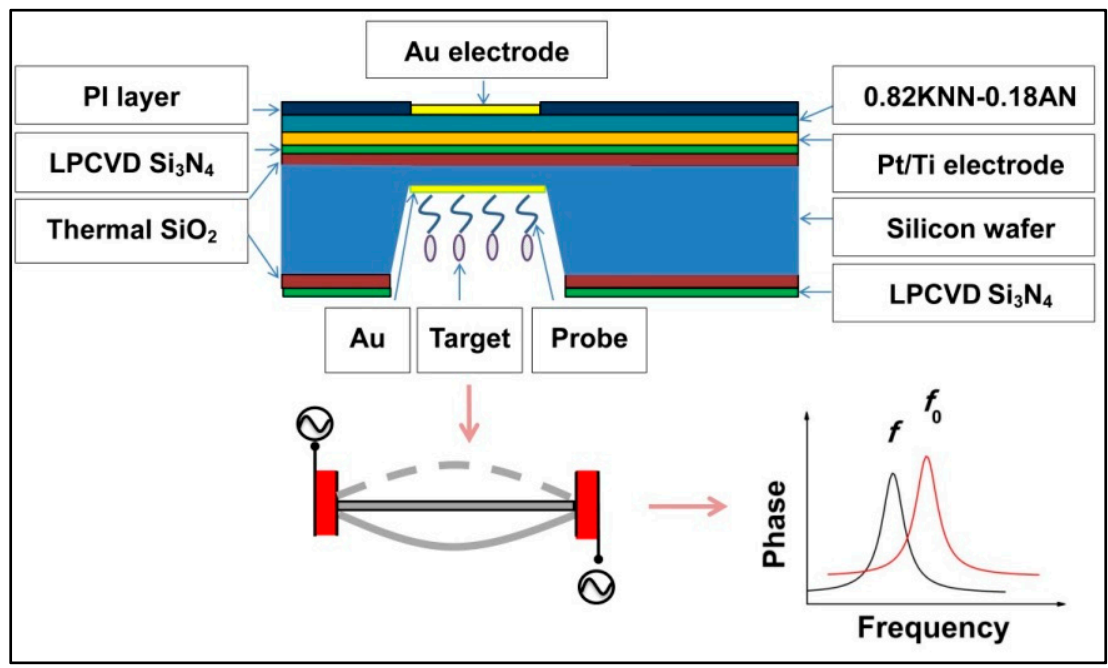

Figure 9. Schematic drawings and principle of the piezoelectric diaphragm biosensor.

The resonant frequency of a square diaphragm with length of $a$ can be expressed as $[25,28,31,32]$ : 


$$
f_{0}=\frac{1}{2 \pi a^{2}} \sqrt{\frac{\gamma^{4} D}{\rho h}}
$$

where $f_{0}$ is the resonant frequency, $\rho$ is the diaphragm density, $h$ is the diaphragm thickness, $\gamma$ is a constant and $D$ is the flexural rigidity, respectively. The definition of mass sensitivity of the biosensor is the resonant frequency change corresponding to a unit mass load, which can be defined as $[25,33]$ :

$$
S_{m}=-\frac{\Delta f}{\Delta m}
$$

where $\Delta m$ is the mass change per unit area, the $\Delta f$ is the resonant frequency shift. A larger value of $S_{m}$ means that the biosensor is more mass sensitive.

\subsection{Fabrication of the Piezoelectric Diaphragm Biosensor}

The piezoelectric diaphragms were fabricated by combining the chemical solution deposition method with traditional silicon micromachining technology; the fabrication processing steps are shown in Figure 10. In summary, the fabrication process was composed of nine main steps. (1) A layer of $1.5 \mu \mathrm{m}$-thick thermal $\mathrm{SiO}_{2}$ was grown on a 4" double-sided polished silicon wafer; (2) A silicon nitride layer of $200 \mathrm{~nm}$ was then deposited by low pressure chemical vapour deposition (LPCVD) on both sides of the wafer; (3) The diaphragm windows on the backside were opened by dry etching of $\mathrm{Si}_{3} \mathrm{~N}_{4}$ and wet etching of $\mathrm{SiO}_{2}$, which were realized by inductive coupled plasma (ICP) using $\mathrm{SF}_{6}+\mathrm{He}$ and by buffered oxide etchant (BOE, which was composed of $\mathrm{HF}, \mathrm{NH}_{4} \mathrm{~F}$ and $\mathrm{H}_{2} \mathrm{O}$ ), respectively; (4) The backside silicon was anisotropic wet etched by $\mathrm{KOH}$ until the remaining thickness of silicon was about $50 \mu \mathrm{m}$; (5) Pt/Ti layer of $200 \mathrm{~nm} / 20 \mathrm{~nm}$ were sputtered on the front side of wafer as the bottom electrode; (6) $0.82 \mathrm{KNN}-0.18 \mathrm{AN}$ layer was deposited using the chemical solution deposition technique to serve as the piezoelectric layer; (7) A polyimide (PI) layer of $2 \mu \mathrm{m}$ was spin-coated, patterned and cured as an insulation layer to minimize parasitic capacitance induced by the patterned electrode wiring; (8) Au layer of $80 \mathrm{~nm}$ to serve as top electrode was sputtered and patterned by lift-off process; (9) Finally, the backside silicon was etched off by ICP using $\mathrm{SF}_{6}+\mathrm{O}_{2}+\mathrm{C}_{4} \mathrm{~F}_{8}$ until the required residual silicon thickness $(20 \sim 25 \mu \mathrm{m})$ was reached.

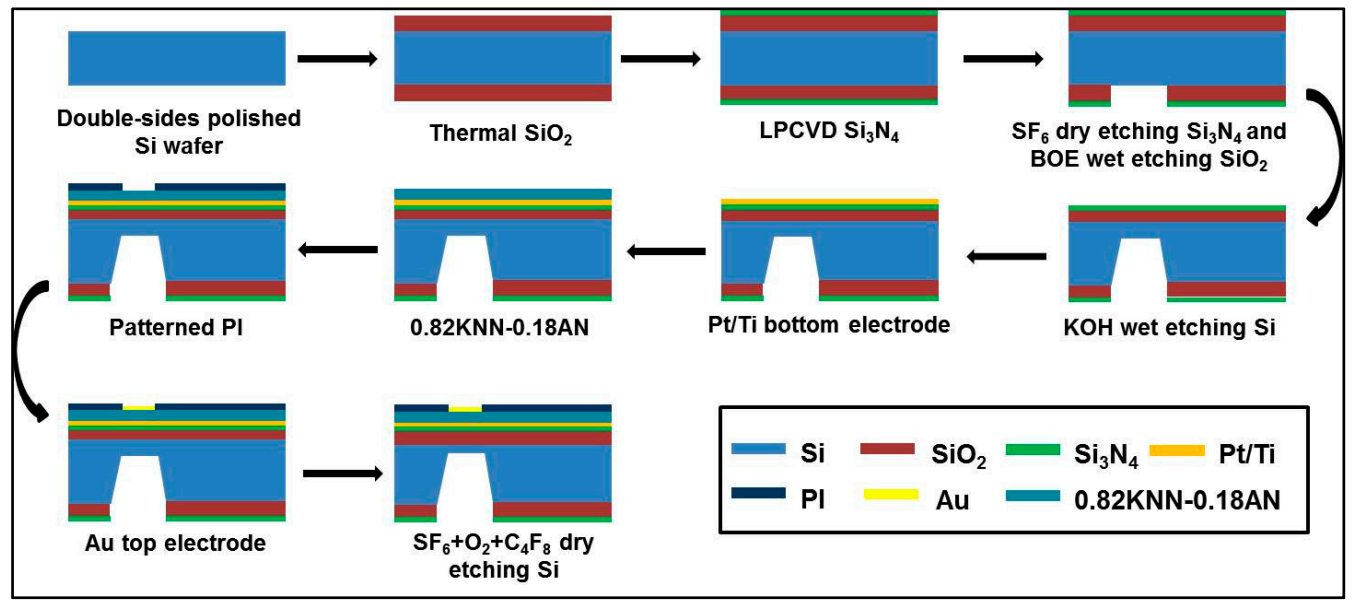

Figure 10. Schematic fabrication process of the piezoelectric diaphragms.

The thickness of the double-sided polished Si wafer was $400 \mu \mathrm{m}$ and the crystal orientation was (100). Square diaphragms were fabricated by the anisotropic wet etching in $30 \mathrm{wt} \% \mathrm{KOH}$ solution at $80^{\circ} \mathrm{C}$ in the oil bath heater.

In the fabrication process, three lithography masks were used for the patterning of silicon diaphragms, the polyimide layer and the top electrodes, which were designed as shown in Figure 11. 
The alignment of the silicon diaphragm mask with the polyimide mask used the double-sided aligning technique while the polyimide mask with the top electrode mask used the overlay aligning technique.

(a)

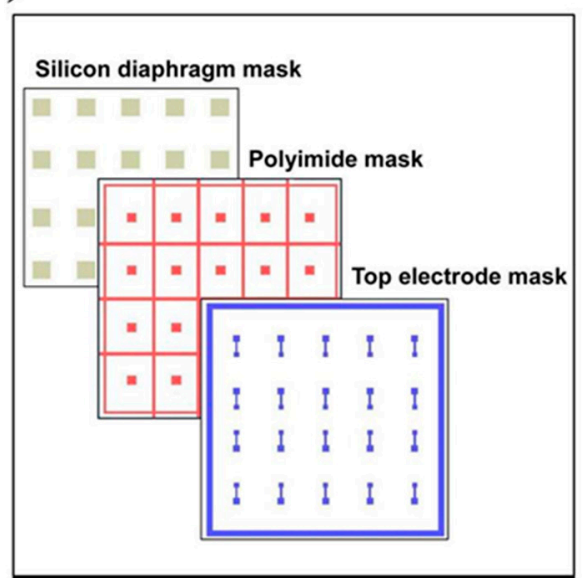

(b)

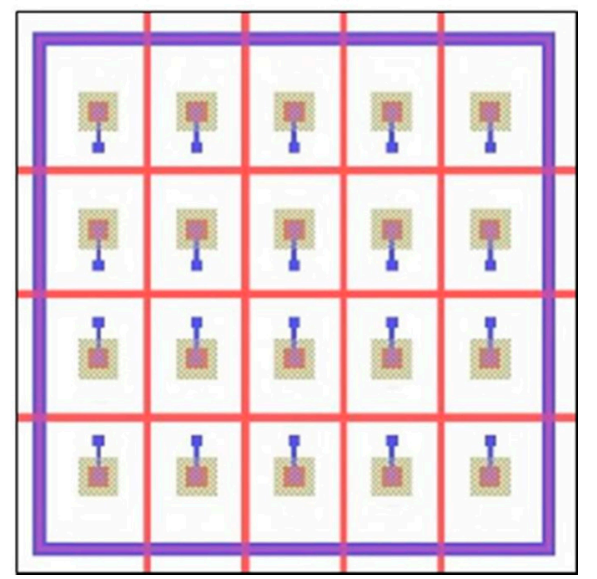

Figure 11. (a) Three masks for the fabrication process; and (b) their alignment image.

The lead-free $0.82 \mathrm{KNN}-0.18 \mathrm{AN}$ thin film layer was deposited using the chemical solution deposition method. For the preparation of the $0.82 \mathrm{KNN}-0.18 \mathrm{AN}$ precursor solution, potassium acetate, sodium acetate, silver acetate and niobium ethoxide were used as the starting chemicals and 2-methoxyethanol was used as the solvent. Polyvinylpyrrolidone (PVP) with a molecular weight of 360,000 was added to enhance the film thickness. The chemical composition was designed as $0.82 \mathrm{~K}_{0.5} \mathrm{Na}_{0.5} \mathrm{NbO}_{3}-0.18 \mathrm{AgNbO}_{3}$. The final concentration of $0.82 \mathrm{KNN}-0.18 \mathrm{AN}$ precursor solution was $0.5 \mathrm{~mol} / \mathrm{L}$. The precursor solution was spin-coated onto the front side of the device at $2000 \mathrm{rpm}$ for $60 \mathrm{~s}$. Then wet film was dried at $100{ }^{\circ} \mathrm{C}$ for $2 \mathrm{~min}$ on a hotplate. The dried film was pyrolyzed at $330{ }^{\circ} \mathrm{C}$ for $5 \mathrm{~min}$ and annealed at $650^{\circ} \mathrm{C}$ for $10 \mathrm{~min}$ in a rapid thermal annealing (RTA) furnace with a heating rate of $50{ }^{\circ} \mathrm{C} / \mathrm{s}$. Four layers were deposited by repeating all the above steps to increase the thickness of the $0.82 \mathrm{KNN}-0.18 \mathrm{AN}$ film.

\subsection{Measurements of the Resonant Frequencies}

The resonant frequencies were measured by the impedance analyzer (Agilent 4294A) at room temperature. The top electrode and bottom electrode were connected to the impedance analyzer using copper wires with a Agilent 42942A terminal adapter. During the measurements, the direct current (DC) bias voltage was fixed at $30 \mathrm{~V}$ and the oscillating (OSC) voltage level was $1 \mathrm{~V}$.

\section{Conclusions}

In this paper, we have developed a novel lead-free piezoelectric diaphragm biosensor, unsing a fabrication process compatible with integrated circuit (IC) technology. The thickness of the piezoelectric film was about $2.16 \mu \mathrm{m}$. The resonant frequencies were measured and the frequency changes were calculated. The mass sensitivity of the biosensor was about $931 \mathrm{~Hz} / \mu \mathrm{g}$. After sensing performance characterization, it was verified that this piezoelectric biosensor can potentially be used for nucleic acid testing. With micro-machining technology and process optimization, the piezoelectric diaphragm biosensors can be miniaturized, so the cost can be further reduced.

Acknowledgments: This work was financially supported by International Science \& Technology Cooperation Program of China (Grant No. 2011DFA51880), the 111 Project of China (B14040), the Shaanxi Province International Collaboration Program (Grant No. 2012KW-02), the Shaanxi Science \& Technology Promotion Program(2011TG-08), the Qianren Program of the Chinese Government, the Natural Science and Engineering Research Council of Canada (NSERC), and the United States Office of Naval Research (Grant No. N00014-12-1-1045). The SEM work was done at International Center for Dielectric Research (ICDR), Xi'an Jiaotong University, Xi'an, China; 
The authors also thank Yijun Zhang for his help in using SEM. The authors also thank Bei Zhao and Jie Hu for their help in DNA testing experiments.

Author Contributions: All the authors conceived and designed the experiments. Xiaomeng Li performed the experiments; Xiaomeng Li and Xiaoqing Wu analyzed the data; Xiaoqing Wu, Peng Shi and Zuo-Guang Ye supervised and reviewed the manuscript.

Conflicts of Interest: The authors declare no conflict of interest.

\section{References}

1. Mehrabani, S.; Maker, A.J.; Armani, A.M. Hybrid Integrated Label-Free Chemical and Biological Sensors. Sensors 2014, 14, 5890-5928. [CrossRef] [PubMed]

2. Kim, S.K.; Cho, H.; Park, H.J.; Kwon, D.; Lee, J.M.; Chung, B.H. Nanogap biosensors for electrical and label-free detection of biomolecular interactions. Nanotechnology 2009, 20, 455502. [CrossRef] [PubMed]

3. Esfandyarpour, R.; Javanmard, M.; Koochak, Z.; Esfandyarpour, H.; Harris, J.S.; Davis, R.W. Label-free electronic probing of nucleic acids and proteins at the nanoscale using the nanoneedle biosensor. Biomicrofluidics 2013, 7, 044114. [CrossRef] [PubMed]

4. Esfandyarpour, R.; Esfandyarpour, H.; Javanmard, M.; Harris, J.S.; Davis, R.W. Microneedle biosensor: A method for direct label-free real time protein detection. Sens. Actuators B Chem. 2013, 177, 848-855. [CrossRef] [PubMed]

5. Goda, T.; Miyahara, Y. Label-free and reagent-less protein biosensing using aptamer-modified extended-gate field-effect transistors. Biosens. Bioelectron. 2013, 45, 89-94. [CrossRef] [PubMed]

6. Goda, T.; Tabata, M.; Sanjoh, M.; Uchimura, M.; Iwasaki, Y.; Miyahara, Y. Thiolated 2-methacryloyloxyethyl phosphorylcholine for an antifouling biosensor platform. Chem. Commun. 2013, 49, 8683-8685. [CrossRef] [PubMed]

7. Miller, T.R.; Skoog, S.A.; Edwards, T.L.; Lopez, D.M.; Wheeler, D.R.; Arango, D.C.; Xiao, X.; Brozik, S.M.; Wang, J.; Polsky, R.; et al. Multiplexed microneedle-based biosensor array for characterization of metabolic acidosis. Talanta 2012, 88, 739-742. [CrossRef] [PubMed]

8. Yaseen, M.T.; Yang, Y.C.; Shih, M.H.; Chang, Y.C. Optimization of High-Q Coupled Nanobeam Cavity for Label-Free Sensing. Sensors 2015, 15, 25868-25881. [CrossRef]

9. Yang, Z.P.; Liu, X.; Zhang, C.J.; Liu, B.Z. A high-performance nonenzymatic piezoelectric sensor based on molecularly imprinted transparent $\mathrm{TiO}_{2}$ film for detection of urea. Biosens. Bioelectron. 2015, 74, 85-90. [CrossRef] [PubMed]

10. Neves, M.A.; Blaszykowski, C.; Bokhari, S.; Thompson, S. Ultra-high frequency piezoelectric aptasensor for the label-free detection of cocaine. Biosens. Bioelectron. 2015, 72, 383-392. [CrossRef] [PubMed]

11. Kim, S.; Choi, S.J. A lipid-based method for the preparation of a piezoelectric DNA biosensor. Anal. Biochem. 2014, 458, 1-3. [CrossRef] [PubMed]

12. Tsai, J.Z.; Chen, C.J.; Shie, D.T.; Liu, J.T. Resonant efficiency improvement design of piezoelectric biosensor for bacteria gravimetric sensing. Biomed. Mater. Eng. 2014, 24, 3597-3604. [PubMed]

13. Su, L.; Zou, L.; Fong, C.C.; Wong, W.L.; Wei, F.; Wong, K.Y.; Wu, R.S.; Yang, M. Detection of cancer biomarkers by piezoelectric biosensor using PZT ceramic resonator as the transducer. Biosens. Bioelectron. 2013, 46, 155-161. [CrossRef] [PubMed]

14. Alava, T.; Mathieu, F.; Rameil, P.; Morel, Y.; Soyer, C.; Remiens, D.; Nicu, L. Piezoelectric-actuated, piezoresistive-sensed circular micromembranes for label-free biosensing applications. Appl. Phys. Lett. 2010, 97, 093703. [CrossRef]

15. Wang, Z.; Miao, J.; Zhu, W. Micromachined ultrasonic transducers and arrays based on piezoelectric thick film. Appl. Phys. A 2008, 91, 107-117. [CrossRef]

16. Wang, Z.; Miao, J.; Zhu, W. Piezoelectric thick films and their application in MEMS. J. Eur. Ceram. Soc. 2007, 27, 3759-3764. [CrossRef]

17. Laser, D.J.; Santiago, J.G. A review of micropumps. J. Micromech. Microeng. 2004, 14, R35-R64. [CrossRef]

18. Perçin, G.K.; Yakub, K.; Butrus, T. Micromachined droplet ejector arrays for controlled ink-jet printing and deposition. Rev. Sci. Instrum. 2002, 73, 2193. [CrossRef] 
19. Hao, R.Z.; Song, H.B.; Zuo, G.M.; Yang, R.F.; Wei, H.P.; Wang, D.B.; Cui, Z.Q.; Zhang, Z.; Cheng, Z.X.; Zhang, X.E. DNA probe functionalized QCM biosensor based on gold nanoparticle amplification for Bacillus anthracis detection. Biosens. Bioelectron. 2011, 26, 3398-3404. [CrossRef] [PubMed]

20. Yao, C.; Zhu, T.; Tang, J.; Wu, R.; Chen, Q.; Chen, M.; Zhang, B.; Huang, J.; Fu, W. Hybridization assay of hepatitis B virus by QCM peptide nucleic acid biosensor. Biosens. Bioelectron. 2008, 23, 879-885. [CrossRef] [PubMed]

21. Sankaran, S.; Panigrahi, S.; Mallik, S. Olfactory receptor based piezoelectric biosensors for detection of alcohols related to food safety applications. Sens. Actuators B Chem. 2011, 155, 8-18. [CrossRef]

22. Johnson, B.N.; Mutharasan, R. Biosensing using dynamic-mode cantilever sensors: A review. Biosens. Bioelectron. 2012, 32, 1-18. [CrossRef] [PubMed]

23. Arora, P.; Sindhu, A.; Dilbaghi, N.; Chaudhury, A. Biosensors as innovative tools for the detection of food borne pathogens. Biosens. Bioelectron. 2011, 28, 1-12. [CrossRef] [PubMed]

24. Xiao, Y.; Liu, Y.; Borg, G.; Li, C.M. Design of a novel disposable piezoelectric co-polymer diaphragm based biosensor unit. Mater. Sci. Eng. C 2011, 31, 95-98. [CrossRef]

25. Xu, T.; Wang, Z.; Miao, J.; Yu, L.; Li, C.M. Micro-machined piezoelectric membrane-based immunosensor array. Biosens. Bioelectron. 2008, 24, 638-643. [CrossRef] [PubMed]

26. Hwang, I.H.; Lee, J.H. Self-actuating biosensor using a piezoelectric cantilever and its optimization. J. Phys. Conf. Ser. 2006, 34, 362-367. [CrossRef]

27. Nicu, L.; Guirardel, M.; Chambosse, F.; Rougerie, P.; Hinh, S.; Trevisiol, E.; Francois, J.; Majoral, J.; Caminade, A.; Cattan, E.; et al. Resonating piezoelectric membranes for microelectromechanically based bioassay: Detection of streptavidin-gold nanoparticles interaction with biotinylated DNA. Sens. Actuators $B$ Chem. 2005, 110, 125-136. [CrossRef]

28. Olfatnia, M.; Singh, V.R.; Xu, T.; Miao, J.M.; Ong, L.S. Analysis of the vibration modes of piezoelectric circular microdiaphragms. J. Micromech. Microeng. 2010, 20, 085013. [CrossRef]

29. Zhao, B.; Hu, J.; Ren, W.; Xu, F.; Wu, X.; Shi, P.; Ye, Z. A new biosensor based on PVDF film for detection of nucleic acids. Ceram. Int. 2015, 41, S602-S606. [CrossRef]

30. Li, X.; Wu, X.; Ren, W.; Shi, P.; Ye, Z. Preparation and characterization of sodium potassium niobate-silver niobate lead-free films by chemical solution deposition. Ceram. Int. 2015, 41, S228-S233. [CrossRef]

31. Xu, T.; Miao, J.; Wang, Z.; Yu, L.; Li, C.M. Micro-piezoelectric immunoassay chip for simultaneous detection of Hepatitis B virus and $\alpha$-fetoprotein. Sens. Actuators B Chem. 2011, 151, 370-376. [CrossRef]

32. Olfatnia, M.; Xu, T.; Ong, L.S.; Miao, J.M.; Wang, Z.H. Investigation of residual stress and its effects on the vibrational characteristics of piezoelectric-based multilayered microdiaphragms. J. Micromech. Microeng. 2010, 20, 015007. [CrossRef]

33. Xin, Y.; Li, Z.; Odum, L.; Cheng, Z.Y.; Xu, Z. Piezoelectric diaphragm as a high performance biosensor platform. Appl. Phys. Lett. 2006, 89, 223508. [CrossRef] 